\title{
Fine-tuning of NADH oxidase decreases byproduct accumulation in respiration deficient xylose metabolic Saccharomyces cerevisiae
}

\author{
Jin $\mathrm{Hou}^{\dagger}$, Fan Suo ${ }^{\dagger}$, Chengqiang Wang, Xiaowei Li, Yu Shen and Xiaoming Bao*
}

\begin{abstract}
Background: Efficiently utilizing all available carbon from lignocellulosic feedstock presents a major barrier to the production of economically feasible biofuel. Previously, to enable xylose utilization, we introduced a cofactor-dependent xylose reductase (XR) and xylitol dehydrogenase (XDH) pathway, or a cofactor-independent xylose isomerase (XI) pathway, into Saccharomyces cerevisiae. The resulting strains metabolized xylose with high efficiency. However, in both pathway recombinant strains, the cofactor imbalance caused accumulation of the byproducts glycerol and/or xylitol and reduced the ethanol production efficiency.

Results: In this study, we introduced NADH oxidase from Lactococcus lactis into both XI and XR-XDH pathway recombinant strains. To reduce byproduct accumulation while maintaining xylose metabolism, we optimized the expression level of NADH oxidase by comparing its expression under the control of different promoters and plasmids. In recombinant XI strains, $\mathrm{NADH}$ oxidase was expressed at different levels, regulated by the GPD2 promoter or TEF1 promoter in the $2 \mu$ plasmid. The expression under the control of GPD2 promoter decreased glycerol production by $84 \%$ and increased the ethanol yield and specific growth rate by $8 \%$ and $12 \%$, respectively. In contrast, in the recombinant XR-XDH strains, such expression level was not efficient enough to decrease the byproduct accumulation. Therefore, higher NADH oxidase expression levels were tested. In the strain expressing NADH oxidase under the control of the TEF1 promoter in the centromeric plasmids, xylitol and glycerol production were reduced by $60 \%$ and $83 \%$, respectively, without significantly affecting xylose consumption.

Conclusions: By fine-tuning NADH oxidase expression, we decreased the glycerol or/and xylitol production in both recombinant XI and XR-XDH xylose-metabolizing yeast strains. The optimal NADH oxidase expression levels depend on metabolic pathways. Similar cofactor engineering strategies could maximize the production of other redox dependent metabolites.
\end{abstract}

Keywords: NADH oxidase, Xylose metabolism pathways, Cofactor, Glycerol, Xylitol

\section{Background}

Efficient utilization of all available carbon from lignocellulosic feedstock presents a major barrier to economical biofuel production [1]. Xylose is the second predominant sugar in lignocellulosic feedstock after glucose. However, Saccharomyces cerevisiae, which is ubiquitously employed in ethanol production, cannot naturally metabolize xylose. Consequently, throughout the past few decades, the introduction of xylose metabolic pathways into S. cerevisiae has

\footnotetext{
* Correspondence: bxm@sdu.edu.cn

${ }^{\dagger}$ Equal contributors

State Key Laboratory of Microbial Technology, Shandong University, Shanda Nan Road 27, Jinan 250100, China
}

been extensively researched [2,3]. Two pathways have been studied widely for D-xylose utilization. In fungi and xylosemetabolic yeasts, D-xylose is reduced to xylitol by $\mathrm{NAD}(\mathrm{P})$ $\mathrm{H}$-dependent xylose reductase (XR), encoded by XYL1 and xylitol is then oxidized to $\mathrm{D}$-xylulose by $\mathrm{NAD}^{+}$-dependent xylitol dehydrogenase (XDH), encoded by XYL2 $[4,5]$. The resulting D-xylulose is converted to xylulose-5-phosphate by endogenous xylulose kinase (XK). Alternatively, some bacteria and fungi can directly convert D-xylose to xylulose via the cofactor-independent xylose isomerase (XI) pathway. Both pathways have been successfully introduced into S. cerevisiae, allowing the recombinant strains to produce ethanol from xylose (Figure 1) [6-11]. Xylose metabolism 


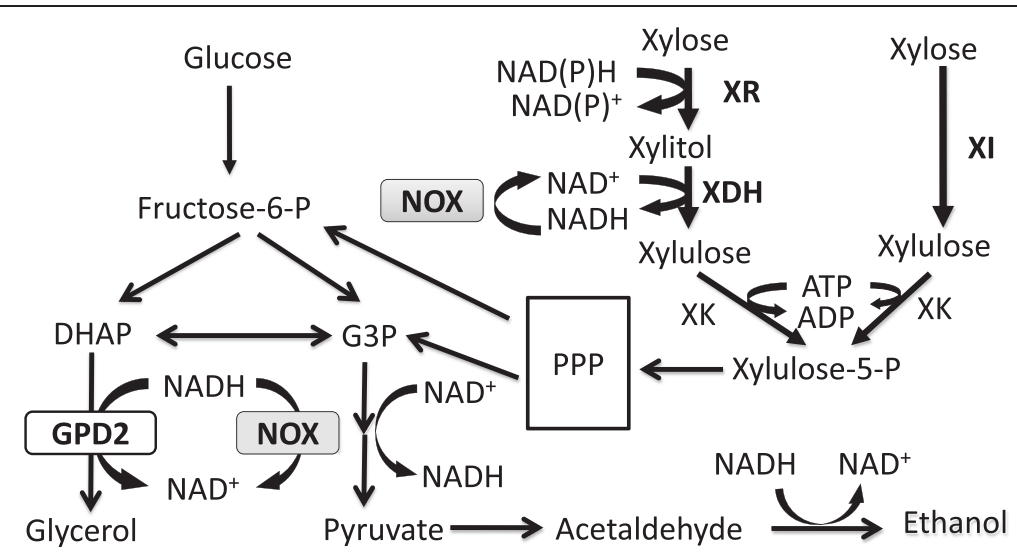

Figure 1 Glucose and xylose metabolic pathways in recombinant S. cerevisiae. The introduction NADH oxidase can reduce the amount of excess NADH which is normally produced by glycerol 3-phosphate dehydrogenase (GPD) or xylitol dehydrogenase (XDH).

has been improved by over-expressing the endogenous xylulose kinase genes and the genes involved in the nonoxidative pentose phosphate pathway $[12,13]$.

Introducing the Scheffersomyces stipitis $\mathrm{XR}-\mathrm{XDH}$ pathway into $S$. cerevisiae has enabled the yeast to effectively utilize xylose $[4,5,14]$. Our previous work also demonstrated efficient xylose uptake by strains expressing this pathway $[12,15]$. However, the different cofactor dependence of XR and XDH leads to cofactor imbalance and xylitol accumulation. Recent studies have focused on metabolic engineering to balance intracellular cofactor levels or on modifying the cofactor specificities of $\mathrm{XR}$ or $\mathrm{XDH}$ to establish an oxidation-reduction cycle [16-20]. Several strategies have been implemented for balancing intracellular cofactors in recombinant $S$. cerevisiae. These include manipulating ammonia assimilation from being NADPH dependent to being NADH dependent by replacing GDH1 (which encodes NADPHdependent glutamate dehydrogenase) with GDH2 (which encodes NADH-dependent glutamate dehydrogenase), expressing the Kluyveromyces lactis GDP1 gene, which encodes a fungal NADP ${ }^{+}$-dependent $\mathrm{D}$-glyceraldehyde3-phosphate dehydrogenase, expressing the gapN gene from Streptococcus mutants, which encodes a nonphosphorylating $\mathrm{NADP}^{+}$-dependent GAPDH, and overexpressing the truncated POS5 gene, which encodes cytosolic NADH kinase $[15,19,21,22]$.

An alternative pathway for xylose catabolism is the isomerase-based pathway. This pathway is cofactor independent, and therefore could lead to higher theoretical ethanol yields. However, only a few xylose isomerase genes have been successfully expressed in S. cerevisiae, derived from organisms such as Piromyces sp. [6,23], Orpinomyces sp. [24], Clostridium phytofermentans [25] and Prevotella ruminicola [26]. Further engineering strategies, such as adaptive evolutionary engineering [8] and over-expressing downstream pathways $[7,27]$, have been implemented to improve xylose consumption and cell growth.

Recently, we obtained a new XI ( $x y l A)$ gene from bovine rumen. The activity of this XI in S. cerevisiae was slightly higher than the XI from Piromyces sp. [28]. We also engineered the host strain to over-express the endogenous xylulose kinase gene (XKS1) and the genes in non-oxidative pentose phosphate pathway, eliminating the respiration by deleting cytochrome $\mathrm{C}$ oxidase subunit IV encoding gene COX4, and adaptive evolution [13]. The recombinant strain showed high xylose metabolism capability and high ethanol yield under both aerobic and anaerobic conditions. However, although no xylitol was accumulated, substantial amounts of glycerol were produced as the major byproduct [28].

In industrial ethanol processes, up to $4 \%$ of the sugar feedstock is converted into glycerol by $S$. cerevisiae, which is an unwanted loss of carbon source [29,30]. Glycerol synthesis plays important roles in yeast osmoregulation and in regulating intracellular redox balance [31]. It is produced from dihydroxyacetone phosphate (DHAP) through the catalysis of glycerol-3-phosphate dehydrogenase (GPD, encoded by genes GPD1 and GPD2) and glycerol-3phosphate phosphatase (GPP, encoded by genes GPP1 and GPP2). Researchers have expended considerable effort in minimizing glycerol formation. One approach is to delete one or both of GPD1 and GPD2 as well as the genes involved in glycerol transport, such as FPS1 [32,33]. Because cells lacking the GPD1 and GPD2 genes cannot grow anaerobically, the promoter of GPD1 has been engineered in GPD2 deletion background [34]. Alternative approaches aim at manipulating the redox cofactor metabolism to reduce cytosolic NADH accumulation [35]. For example, Nissen et al. deleted GDH1 (encoding NADPH-dependent glutamate dehydrogenase), while overexpressing GLN1 and GLT1 (encoding glutamine synthetase and glutamate synthase, respectively). Their engineered strains demonstrated 
reduced glycerol yield and increased ethanol yield [36]. Guo et al. simultaneously deleted GPD1 and introduced the non-phosphorylating $\mathrm{NADP}^{+}$-dependent GAPDH gene gap $N$ into strains overexpressing the trehalose synthesis genes TPS1 and TPS2, thereby obtaining a high ethanolyielding strain [32]. Zhang et al. combined the expression of $\mathrm{NADP}^{+}$-dependent GAPDH gene gapN with either a $\mathrm{NAD}^{+}$-dependent fumarate reductase gene $f r d A$, or an acetylating $\mathrm{NAD}^{+}$-dependent acetaldehyde dehydrogenase for reoxidizing NADH [37].

Water-forming $\mathrm{NADH}$ oxidase can oxidize cytosolic $\mathrm{NADH}$ to $\mathrm{NAD}^{+}$, accompanied by a reduction of $\mathrm{O}_{2}$ to $\mathrm{H}_{2} \mathrm{O}$, when oxygen is available. Previous studies have demonstrated the capability of NADH oxidase expression to reduce xylitol production during xylose metabolism [20], but in this approach, aerobic cultivation combined with oxygen-limited fermentation has to be performed to supply oxygen for NADH oxidase, which results in low ethanol production. However, if the ethanol yield is enhanced by purely anaerobic cultivation, the NADH oxidase reaction is deprived of its required oxygen. In our previous work, we demonstrated that respiration-deficient xylose-metabolizing strains can efficiently produce ethanol from xylose and glucose under both aerobic and anaerobic conditions [12]. Therefore, in the present study, we expressed water-forming NADH oxidase derived from Lactococcus lactis in our respirationdeficient xylose-metabolizing strains (Figure 1). The fermentation process is aerobically controlled to supply oxygen for NADH oxidase without compromising ethanol production. The impact on byproduct accumulation and ethanol production was studied in both recombinant XI strains and recombinant XR-XDH strains. To decrease the byproduct accumulation without affecting yeast growth and sugar metabolism, different NADH oxidase expression levels were compared by expressing the noxE gene controlled by different promoters in the
$2 \mu$ or centromeric plasmids under glucose and xylose co-cultivation conditions.

\section{Results}

NADH oxidase expression decreases glycerol production in recombinant XI strains

As mentioned previously, glycerol is the main byproduct of xylose metabolism in recombinant XI strains [7]. We therefore aimed to suppress glycerol production by expressing the NADH oxidase gene. Two different NADH oxidase expression levels were selected under the control of either the TEF1 or GPD2 promoter in the $2 \mu$ plasmid. The relative transcription of noxE in XITN was about 13 fold higher than that in XIGN (Figure 2A). The specific enzyme activities of NADH oxidase in XITN and XIGN were 1.85 and $0.08 \mathrm{U} \mathrm{mg}^{-1}$ protein, respectively (Table 1). As a consequence of NADH oxidase expression, the intracellular $\mathrm{NADH} / \mathrm{NAD}^{+}$ratio decreased by $67 \%$ and $23 \%$ in XITN and XIGN, respectively, relative to XICO (Figure 2B).

We then studied the impact of NADH oxidase expression on glucose and xylose co-cultivations. As shown in Figure 3 and Table 2, expressing NADH oxidase under the strong constitutive TEF1 promoter in the $2 \mu$ plasmid completely suppressed glycerol production, but also significantly reduced glucose and xylose metabolism, and decreased the ethanol yield by about $17 \%$ (relative to the control strain). This may be because the strong NADH oxidase expression in XITN depleted the pool of NADH (Figure 2B). When NADH oxidase was regulated by the GPD 2 promoter in the $2 \mu$ plasmid, the glycerol yield reduced by $84 \%$ in XIGN, while the ethanol yield and specific growth rate increased by $8 \%$ and $12 \%$, respectively (Figure 3B and Table 2). The biomass yield also increased slightly, without significantly affecting the xylose consumption. These results show that expressing $\mathrm{NADH}$ oxidase under the control of the GPD2 promoter

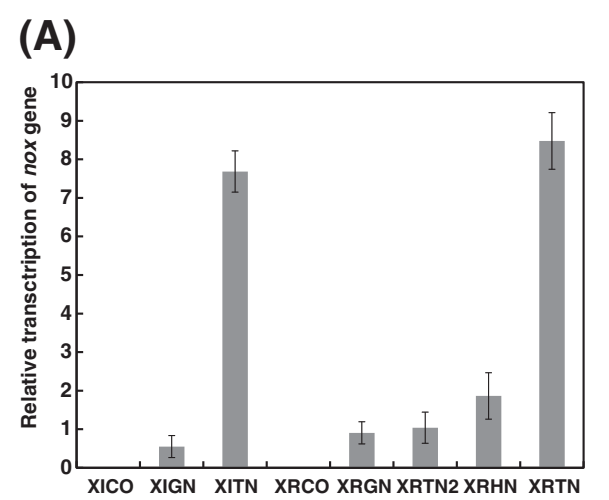

(B)

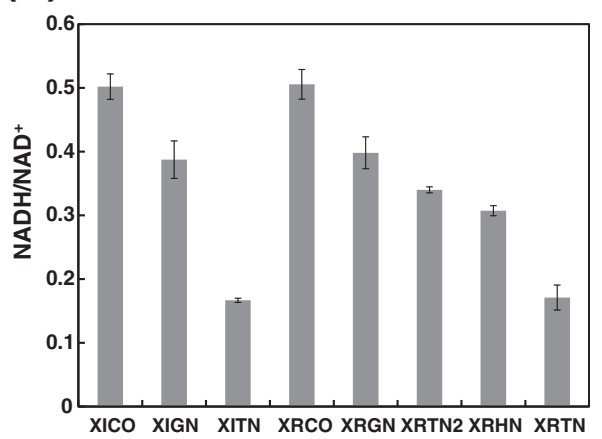

Figure 2 The evaluation of the transcription and expression of noxE gene in the recombinant strains. Relative transcription of noxE gene (A) and intracellular concentrations of $\mathrm{NADH} / \mathrm{NAD}^{+}$ratio (B) in the recombinant strains. Measurements are the average value \pm standard error from independent duplicate experiments. 
Table 1 NADH oxidase activities in recombinant strains of S. cerevisiae

\begin{tabular}{llc}
\hline Strain & Description & $\begin{array}{c}\text { NADH oxidase activity } \\
\text { (U m } \mathbf{~ g}^{-1} \text { total protein) }\end{array}$ \\
\hline XICO & XI, pYX242-WS & 0 \\
XIGN & XI, pYX242-GPD2nox & $0.08 \pm 0.01$ \\
XITN & XI, pYX242-TEF1nox & $1.85 \pm 0.06$ \\
XRCO & XR-XDH, pYX242-WS & 0 \\
XRGN & XR-XDH, pYX242-GPD2nox & $0.05 \pm 0.00$ \\
XRTN2 & XR-XDH, pRS315-TEF1nox & $0.17 \pm 0.00$ \\
XRHN & XR-XDH, pYX242-HXK2nox & $0.57 \pm 0.03$ \\
XRTN & XR-XDH, pYX242-TEF1nox & $1.92 \pm 0.12$ \\
\hline
\end{tabular}

in recombinant XI strains can effectively reduce glycerol production and increase the ethanol yield.

\section{NADH oxidase expression decreases xylitol and glycerol} accumulation in recombinant XR-XDH strains

We also investigated the effect of NADH oxidase expression in recombinant XR-XDH strains (Figure 3 and Table 3). Controlling NADH oxidase expression under the GPD2 promoter was much less effective than in the recombinant XI strains; the glycerol and xylitol yields were reduced by only $50 \%$ and $15 \%$, respectively (Figure $4 \mathrm{~B}$ and Table 3). This suggested that the NADH oxidation level in XRGN was not sufficiently high to suppress byproduct accumulation. However, increased expression under the TEF1 promoter led to a large reduction of ethanol yield and inhibited glucose or xylose consumption, indicating that NADH oxidation level in XRTN were prohibitively high (Figure 4E and Table 3). Therefore, we introduced two medium levels of noxE expression, under the control of the $H X K 2$ promoter in the $2 \mu$ plasmid (strain XRHN) and the TEF1 promoter in the centromeric plasmid (strain XRTN2). The transcription levels of the noxE gene and the specific enzyme activities of NADH oxidase were then compared. The relative transcriptions of noxE in XITN and XRHN were about 7 fold and 1 fold higher than in XRTN2, respectively, while the relative transcription of noxE in XIGN was slightly lower than in XRTN2 (Figure 2A). The specific enzyme activities of NADH oxidase in XRTN, XRHN, XRTN2 and XIGN were 1.92, $0.57,0.17$ and $0.05 \mathrm{U} \mathrm{mg}^{-1}$ protein respectively (Table 1). Relative to $\mathrm{XRCO}$, the intracellular $\mathrm{NADH} / \mathrm{NAD}^{+}$ratio decreased by $66 \%, 39 \%, 33 \%$ and $21 \%$ in XRTN, XRHN, XRTN2 and XRGN, respectively, when NADH oxidase was expressed (Figure 2B).

As shown in Figure 4, although glycerol and xylitol accumulation was completely prevented in XRHN, the specific xylose consumption rate was $35 \%$ lower than in the control strain XRCO (Figure 4D and Table 3). However, in strain XRTN2, the glycerol yield and xylitol accumulation were reduced by $83 \%$ and $60 \%$ respectively, but the specific xylose consumption rate was $21 \%$ lower than in XRCO (Figure 4C and Table 3). Relative to the control strain, byproduct formation was reduced in strain XRTN2 without significantly affecting xylose metabolism. However, none of the recombinant strains improved the ethanol yield relative to XRCO. This indicates that, although $\mathrm{NADH}$ oxidase decreased glycerol and xylitol production in recombinant XR-XDH strains, it did not increase the ethanol production in recombinant XR-XDH pathway strains.

\section{Discussion}

In the presence of oxygen, water-forming NADH oxidase can oxidize cytosolic NADH to $\mathrm{NAD}^{+}$, with simultaneous reduction of $\mathrm{O}_{2}$ to $\mathrm{H}_{2} \mathrm{O}$. Although NADH oxidase expression is known to reduce xylitol production during xylose metabolism, it requires aerobic cultivation combined with oxygen-limited fermentation; otherwise the enzyme cannot function [20]. However, aerobic cultivation reduces ethanol production. Our respiratory-deficient strain can

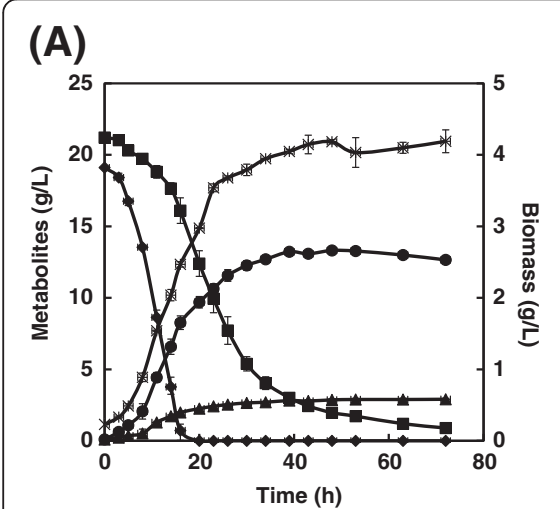

(B)

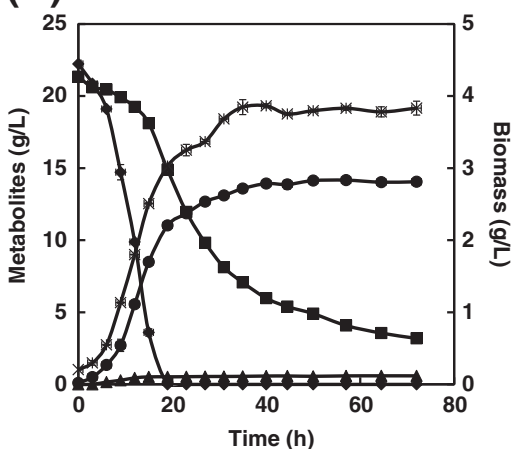

(C)

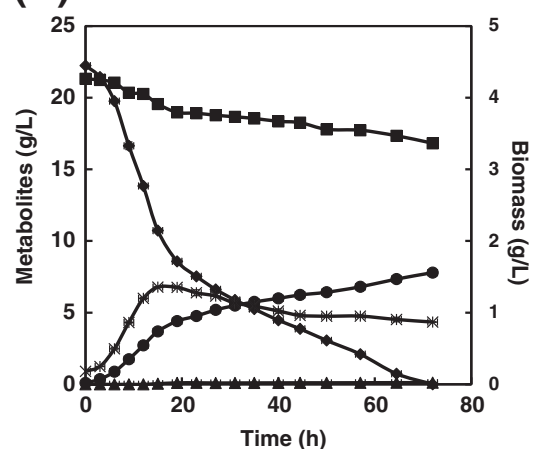

Figure 3 Aerobic batch cultivations of recombinant XI strains with a mixture of $\mathbf{2 0} \mathrm{g} / \mathrm{L}$ glucose and $\mathbf{2 0} \mathrm{g} / \mathrm{L}$ xylose. The experiments were performed in duplicate. (A), XICO; (B), XIGN; and (C), XITN. Symbols: $\bullet$ glucose; $\mathbf{m}$, xylose; $\bullet$, ethanol; $\mathbf{\Delta}$, glycerol; $\times$, biomass. Measurements are the average value \pm standard error from independent duplicate cultivations. 
Table 2 Physiological parameters of recombinant S. cerevisiae strains from batch cultivations on glucose and xylose

\begin{tabular}{|c|c|c|c|c|c|c|c|c|}
\hline \multirow[t]{2}{*}{ Strain } & \multirow[t]{2}{*}{$\mu_{\max }\left(h^{-1}\right)^{a}$} & \multirow[t]{2}{*}{$\begin{array}{c}\text { Consumed } \\
\text { xylose in } 72 \mathrm{~h}\left(\mathrm{~g} \mathrm{~L}^{-1}\right)\end{array}$} & \multicolumn{2}{|c|}{$\begin{array}{l}\text { Sugar consumption } \\
\text { rate }\left(\mathrm{g} \mathrm{L}^{-1} \mathrm{~h}^{-1}\right)^{\mathrm{b}}\end{array}$} & \multicolumn{3}{|c|}{ Yield on sugars $\left(\mathrm{g} \mathrm{g}^{-1}\right)^{\mathrm{c}}$} & \multirow[t]{2}{*}{ Carbon balance } \\
\hline & & & Glucose & Xylose & Biomass & Ethanol & Glycerol & \\
\hline $\mathrm{XICO}$ & 0.17 & 20.14 & 1.34 & 0.48 & 0.10 & 0.35 & 0.084 & 0.92 \\
\hline$X I G N$ & 0.19 & 18.81 & 1.33 & 0.46 & 0.12 & 0.38 & 0.021 & 0.97 \\
\hline XITN & 0.16 & 4.50 & 0.73 & 0.14 & 0.10 & 0.29 & 0.003 & 0.90 \\
\hline
\end{tabular}

Average values from independent duplicate cultivations. In all cases, the standard error is less than $3 \%$.

${ }^{a}$ Maximum specific growth rate $\left(\mathrm{h}^{-1}\right)$.

${ }^{b}$ Specific volumetric rate of glucose or xylose $\left(\mathrm{g} \mathrm{L}^{-1} \mathrm{~h}^{-1}\right)$.

'Biomass, ethanol or glycerol yield on consumed sugars ( $\mathrm{g} \mathrm{g}^{-1}$ sugar).

efficiently generate ethanol from aerobic glucose and $x y-$ lose cultivations. As such, it provides a solid platform for NADH oxidase expression [12].

During the catabolism of glucose or xylose through the XI pathway, S. cerevisiae yields a surplus of cytosolic $\mathrm{NADH}$, mainly through biosynthesis of proteins, nucleic acids and lipids $[38,39]$. Although cytosolic NADH is required for converting acetaldehyde to ethanol, ethanol production is a redox-neutral process, hence does not contribute to surplus NADH oxidation. The additional $\mathrm{NADH}$ generated from catabolism is oxidized via the mitochondrial electron transport chain and glycerol production. In the recombinant XR-XDH strains, the cofactor imbalance between $\mathrm{XR}$ and $\mathrm{XDH}$ and the increase in cytosolic NADH generated by XDH lead to xylitol accumulation and low ethanol conversion. The difference in cytosolic NADH accumulation between these two situations alters the requirement for NADH oxidase. Indeed, we observed that the recombinant XR-XDH strains required higher $\mathrm{NADH}$ oxidase expression than the recombinant XI strain to eliminate glycerol and xylitol.

Glycerol production is consequent to accumulation of excess NADH in the cytosol [40]. The glycerol formation reaction is mediated by glycerol 3-phosphate dehydrogenase (encoded by genes GPD1 and GPD2). Gpd1p is involved in osmosensing and regulation, while Gpd2p is responsible for reoxidation of excess cytosolic NADH [41]. When NADH oxidase is expressed under the control of the GPD2 promoter, the enzyme competes to oxidize excess NADH that is normally reoxidized by glycerol 3-phosphate dehydrogenase during glycerol production. Therefore, NADH oxidase could be fine-tuned in strain XIGN to eliminate glycerol production without draining the NADH pool. Conversely, when NADH oxidase was expressed under the control of the GPD2 promoter in the recombinant XR-XDH strains, the excess cytosolic NADH production reduced the effect of the enzyme. Consequently, the expressed $\mathrm{NADH}$ oxidase was insufficient to eliminate both xylitol and glycerol, and higher expression was necessary. Although xylitol and glycerol production was completely inhibited in the XRHN (in which NADH oxidase expression is controlled by the HXK2 promoter on the $2 \mu$ plasmid), $x y-$ lose consumption by this strain was decreased by $35 \%$ relative to the control strain. XRTN2 (in which NADH oxidase expression is controlled by the TEF1 promoter on the centromeric plasmid) demonstrated lower NADH oxidase activity than XRHN, and yielded low xylitol and glycerol levels without significantly compromising xylose consumption. However, xylose metabolism was decreased by $21 \%$ in this strain and some xylitol accumulation was observed. This indicates that NADH oxidase

Table 3 Physiological parameters of recombinant S. cerevisiae strains from batch cultivations on glucose and xylose

\begin{tabular}{|c|c|c|c|c|c|c|c|c|c|}
\hline \multirow[t]{2}{*}{ Strain } & \multirow[t]{2}{*}{$\mu_{\max }\left(h^{-1}\right)^{a}$} & \multirow[t]{2}{*}{$\begin{array}{l}\text { Consumed xylose } \\
\text { in } 78 \mathrm{~h}\left(\mathrm{~g} \mathrm{~L}^{-1}\right)\end{array}$} & \multicolumn{2}{|c|}{$\begin{array}{l}\text { Sugar consumption } \\
\text { rate }\left(\mathrm{g} \mathrm{L}^{-1} \mathrm{~h}^{-1}\right)^{\mathrm{b}} \\
\end{array}$} & \multicolumn{3}{|c|}{ Yield on sugars $\left(\mathrm{g} \mathrm{g}^{-1}\right)^{c}$} & \multirow[t]{2}{*}{ Xylitol yield $\left(\mathrm{g} \mathrm{g}^{-1}\right)^{d}$} & \multirow[t]{2}{*}{ Carbon balance } \\
\hline & & & Glucose & Xylose & Biomass & Ethanol & Glycerol & & \\
\hline $\mathrm{XRCO}$ & 0.17 & 18.53 & 1.37 & 0.37 & 0.085 & 0.35 & 0.121 & 0.53 & 0.90 \\
\hline $\mathrm{XRGN}$ & 0.18 & 18.47 & 1.39 & 0.37 & 0.094 & 0.37 & 0.035 & 0.45 & 0.86 \\
\hline XRTN2 & 0.16 & 13.79 & 1.20 & 0.29 & 0.080 & 0.36 & 0.023 & 0.21 & 0.82 \\
\hline$X R H N$ & 0.17 & 10.69 & 1.18 & 0.24 & 0.098 & 0.35 & 0 & 0.03 & 0.91 \\
\hline XRTN & 0.15 & 3.31 & 0.98 & 0.08 & 0.094 & 0.29 & 0 & 0 & 0.84 \\
\hline
\end{tabular}

Shown are the average values from independent duplicate cultivations. In all cases, the standard error is less than $3 \%$.

a Maximum specific growth rate $\left(\mathrm{h}^{-1}\right)$.

${ }^{b}$ Specific volumetric rate of glucose or xylose $\left(\mathrm{g} \mathrm{L}^{-1} \mathrm{~h}^{-1}\right)$.

c Biomass, ethanol or glycerol yield from consumed sugars ( $\mathrm{g} \mathrm{g}^{-1}$ sugar).

${ }^{\mathrm{d}}$ Xylitol yield on xylose ( $\mathrm{g} \mathrm{g}^{-1}$ xylose). 


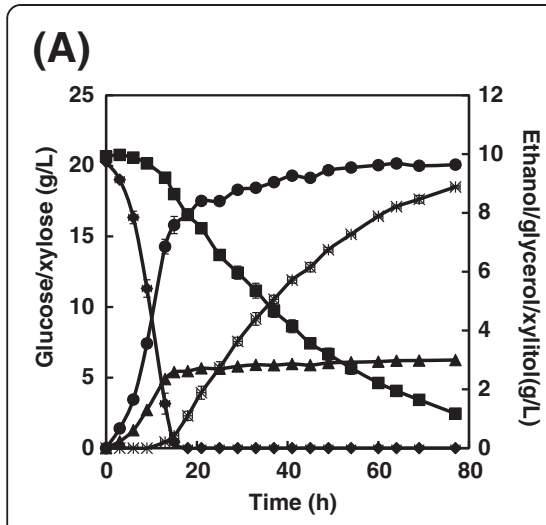

(C)

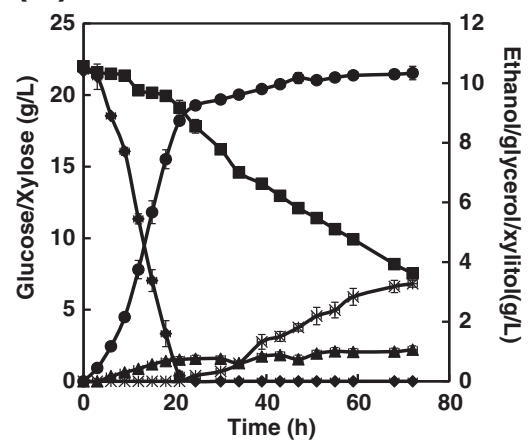

(B)

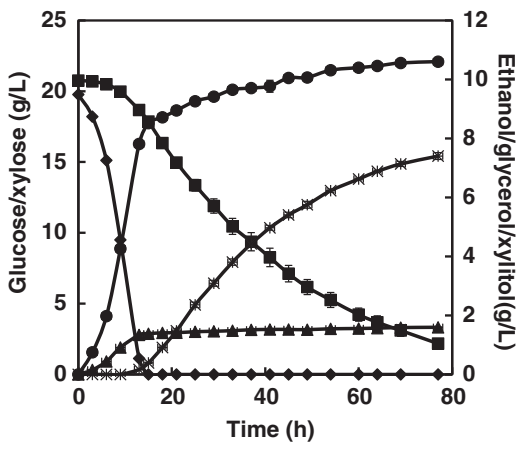

(D)

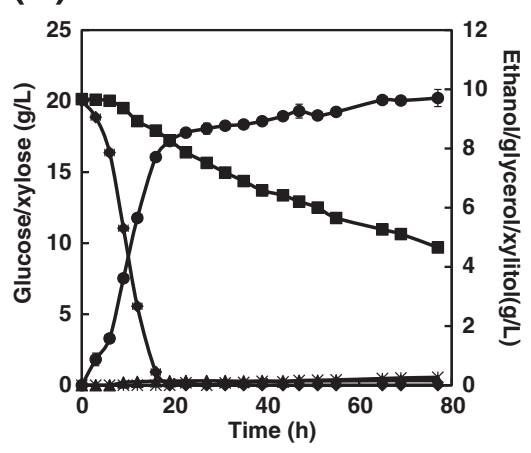

(E)

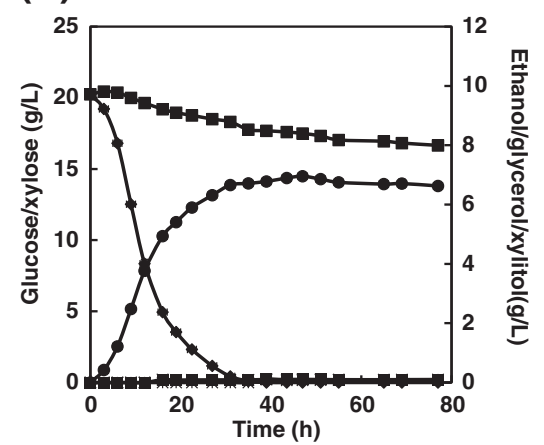

Figure 4 Aerobic batch cultivations of recombinant XR-XDH strains with a mixture of $20 \mathrm{~g} / \mathrm{L}$ glucose and $20 \mathrm{~g} / \mathrm{L}$ xylose. The experiments were performed in duplicate. (A), XRCO; (B), XRGN; (C), XRTN2; (D), XRHN; and (E), XRTN. Symbols: • glucose; $\mathbf{m}$, xylose; • ethanol; $\boldsymbol{\Lambda}$, glycerol; $\times$, xylitol. Measurements are the average value \pm standard error from independent duplicate cultivations.

expression in XRTN2 was insufficient to eliminate byproducts, but was sufficiently high to affect substrate metabolism.

Comparing the optimal modified strains in both pathways, the recombinant XI strain XIGN accumulated little byproduct, and demonstrated a higher xylose consumption rate and ethanol yield than the recombinant XR-XDH strain XRTN2. Therefore, the performance of the recombinant XI strain surpassed that of the recombinant XR$\mathrm{XDH}$ strain. Additionally, our recombinant rumen XI strains XIGN performed similarly to an $S$. cerevisiae strain expressing Piromyces sp. $x y l A[8,11,13]$ in terms of ethanol production, but accumulated considerably less glycerol. Consequently, the recombinant XI strain emerges as a preferable choice for lignocellulosic feedstock utilization.

\section{Conclusion}

In this study, we investigated the impact of NADH oxidase on two xylose metabolism pathways: the cofactor independent XI pathway and the cofactor dependent XR and $\mathrm{XDH}$ pathway. According to our results, NADH oxidase expression decreases glycerol and xylitol accumulation in respiration-deficient xylose-metabolizing $S$. cerevisiae. By controlling the promoter strength of noxE gene and the plasmid copy number, we obtained an efficient xylose-metabolizing strain that accumulated little byproduct. Such fine-tuned cofactor engineering is an attractive strategy for bioprocessing, and is applicable to production of other redox dependent metabolites.

\section{Methods}

\section{Plasmids and strains construction}

The primers used in this study are listed in Table 4. The noxE gene (GenBank Accession no. 4796799) was amplified from the genomic DNA of Lactococcus lactis subsp. MG1363. A $2 \mu$ plasmid pYX242-WS (constructed from pYX242 by inserting the TEF1 promoter in front of the polyA terminator) and a centromeric plasmid pRS315 were used for noxE gene expression. Ligation was performed using T4 DNA ligase or a one-step enzymatic DNA assembly protocol [42]. The noxE gene was constructed under the control of TEF1, GPD2 or HXK2 promoters and polyA terminator in pYX242-WS [42], or the TEF1 promoter and polyA terminator in pRS315 (Table 5). The genetic reference strain was BSPX042 (ura3-52, XKS1::loxP-TEF1p, gre3(-241,+338)::TPI1p- 
Table 4 Primers used in this study

\begin{tabular}{|c|c|c|c|}
\hline Primer name & Sequence $\left(5^{\prime} \rightarrow 3^{\prime}\right)$ & Template & Purpose \\
\hline Leu2 up & ATGTCTGCCCCTAAGAAGATCGTCGTITGCCAGGTGACAGCTGAAGCTTCGTACGCTG & pUG6 & $\begin{array}{l}\text { LEU2 gene } \\
\text { deletion }\end{array}$ \\
\hline Leu2 down & CACCAGTTCTGATACCTGCATCCAAAACCTIITTAACTGATAGGCCACTAGTGGATCTG & pUG6 & $\begin{array}{l}\text { LEU2 gene } \\
\text { deletion }\end{array}$ \\
\hline TEF1W up & CCCAAGCTTCACAATGCATACTTTGTACGTT ${ }^{a}$ & $\begin{array}{l}\text { BSPX042 } \\
\text { chromosome }\end{array}$ & pYX242-WS \\
\hline TEF1W down & GCGCGTCGACTTGTAATTAAAACTTAGATTAG ${ }^{\mathrm{b}}$ & $\begin{array}{l}\text { BSPX042 } \\
\text { chromosome }\end{array}$ & pYX242-WS \\
\hline noxE up & ACGCGTCGACATGAAAATCGTA ${ }^{c}$ & L. lactis chromosome & pYX242- TEF1nox \\
\hline noxE down & GTCCGAGCTCTTATTTGGCATTC ${ }^{d}$ & L. lactis chromosome & pYX242- TEF1nox \\
\hline GPD2p up & TITAATAACTCGAAAATTCTGCGTTCGTTAAAGCTTCGACATATCTATTATAGTGGGGAGA & $\begin{array}{l}\text { BSPX042 } \\
\text { chromosome }\end{array}$ & pYX242- GPD2nox \\
\hline GPD2p down & GCCTGCGTGGTTTGTACCGATAACTACGATTITCATGTCGACACGACTAGTGACAGCAAGCATT & $\begin{array}{l}\text { BSPX042 } \\
\text { chromosome }\end{array}$ & pYX242- GPD2nox \\
\hline HXK2p up & TAAGTTTAATAACTCGAAAATTCTGCGTTCGTTAAAGCTITGAAAAAAAGTGCGGGGC & $\begin{array}{l}\text { BSPX042 } \\
\text { chromosome }\end{array}$ & pYX242-HXK2nox \\
\hline HXK2p down & CTGCGTGGTITGTACCGATAACTACGATITCATGTCGACTITATTAATTAGCGTACT & $\begin{array}{l}\text { BSPX0 } 42 \\
\text { chromosome }\end{array}$ & pYX242-HXK2nox \\
\hline TEF1p up & TGGAGCTCCACCGCGGTGGCGGCCGCTCTAGAACTAGTGGATCCCACAATGCATACTIT & $\begin{array}{l}\text { BSPX0 } 42 \\
\text { chromosome }\end{array}$ & pRS315-TEF1nox \\
\hline TEF1p down & GGGTACCGGGCCCCCCCTCGAGGTCGACGGTATCGATAAGCTTAGCCGGCGAACGTGGC & $\begin{array}{l}\text { BSPX042 } \\
\text { chromosome }\end{array}$ & pRS315-TEF1nox \\
\hline ACT1qPCR up & CAAACCGCTGCTCAATCTTC & CDNA & qPCR \\
\hline $\begin{array}{l}\text { ACT1qPCR } \\
\text { down }\end{array}$ & AGTITGGTCAATACCGGCAG & CDNA & qPCR \\
\hline NOXqPCR up & TACTGCCAACAGTGCCTTGG & CDNA & qPCR \\
\hline NOXqPCR down & TTCCTGACCGAACAGCGTTT & cDNA & qPCR \\
\hline
\end{tabular}

anderline: Hind III restriction site used for ligation.

${ }^{b}$ underline: Sall restriction site used for ligation.

cunderline: Sall restriction site used for ligation.

${ }^{d}$ underline: Sacl restriction site used for ligation.

RKI1-RKI1t-PGK1p-TAL1-TAL1t-FBA1p-TKL1-TKL1tADH1p-RPE1-RPE1t-loxP, cox4::loxP, adaptive evolution) as described in our previous work [28] (Table 5). The recombinant yeast strains and plasmids used in this study are listed in Table 5. The leucine auxotrophic strain, obtained by deleting the LEU2 gene in BSPX042, was named BSLS000. The recombinant XR-XDH and XI strains were constructed by transforming the pJX1 (XYL1 and $X Y L 2$ genes from S. stipitis) and pJX7 (xylA gene from bovine rumen, GenBank Accession no. JF496707) plasmids, respectively, into BSLS000. The empty plasmid pYX242-WS or plasmids containing the noxE gene was then transformed into the recombinant XR-XDH or XI strains, to construct XICO (XI, pYX242-WS), XITN (XI, pYX242-TEF1nox), XIGN (XI, pYX242-GPD2nox), XRCO (XR-XDH, pYX242-WS), XRTN (XR-XDH, pYX242TEF1nox), XRGN (XR-XDH, pYX242-GPD2nox), XRHN (XR-XDH, pYX242-HXK2nox) and XRTN2 (XR-XDH, pRS315-TEF1nox) (Table 5).

\section{Growth conditions}

E. coli recombinant cells were grown in Luria-Bertani medium $(5 \mathrm{~g} / \mathrm{L}$ yeast extract, $10 \mathrm{~g} / \mathrm{L}$ tryptone, $10 \mathrm{~g} / \mathrm{L} \mathrm{NaCl}$, $\mathrm{pH} 7.0)$ in the presence of ampicillin $(100 \mathrm{mg} / \mathrm{L})$ at $37^{\circ} \mathrm{C}$. Recombinant strains of $S$. cerevisiae were cultured in SD medium $\left(1.7 \mathrm{~g} / \mathrm{L}\right.$ yeast nitrogen base, $\left.5 \mathrm{~g} / \mathrm{L}\left(\mathrm{NH}_{4}\right)_{2} \mathrm{SO}_{4}\right)$ with amino acid lacking uracil and/or leucine and $20 \mathrm{~g} / \mathrm{L}$ glucose at $30^{\circ} \mathrm{C}$, with rotation at $200 \mathrm{rpm}$.

\section{Batch cultivations}

Preculture was prepared by inoculating the strains in $400 \mathrm{~mL} \mathrm{SD}$ medium containing $20 \mathrm{~g} / \mathrm{L}$ glucose in $1 \mathrm{~L}$ shake flasks. The batch cultivations were carried out in $1.4 \mathrm{~L}$ fermenters (Infors AG, Switzerland) with a working volume of $1 \mathrm{~L}$ and controlled at $30^{\circ} \mathrm{C}, 600 \mathrm{rpm}$ and $0.1 \mathrm{vvm}$. The $\mathrm{pH}$ was maintained at 5.0 by automatic addition of $1 \mathrm{M} \mathrm{H}_{3} \mathrm{PO}_{4}$ or $1 \mathrm{M} \mathrm{NaOH}$. The quantity of $\mathrm{CO}_{2}$ and $\mathrm{O}_{2}$ in the exhaust gases was measured with a 
Table 5 Plasmids and strains used in this study

\begin{tabular}{|c|c|c|}
\hline Strain/plasmid & Genotype/properties & $\begin{array}{l}\text { Source of } \\
\text { reference }\end{array}$ \\
\hline \multicolumn{3}{|l|}{ S. cerevisiae } \\
\hline CEN.PK113-5D & MATa SUC2 MAL8C ura3-52 & Peter Kötter \\
\hline $\mathrm{BSPX042}$ & $\begin{array}{l}\text { CEN.PK113-5D, XKS1::IoxP-TEF1p, gre3 } \\
\text { (-241, +338) :-TPI1p-RK11-RK11t-PGK1p- } \\
\text { TAL1-TAL1t-FBA1p-TKL1-TKL1t-ADH1p- } \\
\text { RPE1-RPE1t-loxP, cox4::IoXP, adaptive } \\
\text { evolution, ura3-52 }\end{array}$ & {$[28]$} \\
\hline BSLS000 & BSPX042, leu2::/oxp-KanMX-loxp & This study \\
\hline $\mathrm{XICO}$ & BSLS000, pJX7\&pYX242-WS & This study \\
\hline XITN & BSLS000, pJX7\&pYX242-TEF1nox & This study \\
\hline XIGN & BSLS000, pJX7\&pYX242-GPD2nox & This study \\
\hline $\mathrm{XRCO}$ & BSLS000, pJX1\&pYX242-WS & This study \\
\hline XRTN & BSLS000, pJX1\&pYX242-TEF1nox & This study \\
\hline XRGN & BSLS000, pJX1\&pYX242-GPD2nox & This study \\
\hline $\mathrm{XRHN}$ & BSLS000, pJX1\&pYX242-HXK2nox & This study \\
\hline XRTN2 & BSLS000, pJX1\&pRS315-TEF1nox & This study \\
\hline \multicolumn{3}{|l|}{ Plasmids } \\
\hline pYX242-WS & $\begin{array}{l}2 \mu \text { plasmid with TEF1 promoter } \\
\text { and Poly A terminator, LEU2 marker }\end{array}$ & This study \\
\hline pRS315 & $\begin{array}{l}\text { Centromeric plasmid with } \\
\text { LEU2 marker }\end{array}$ & ATCC77144 \\
\hline pYX242-TEF1nox & $\begin{array}{l}\text { pYX242-WS, noxE gene } \\
\text { with TEF1 promoter, LEU2 }\end{array}$ & This study \\
\hline pYX242-GPD2nox & $\begin{array}{l}\text { pYX242-WS, noxE gene with GPD2 } \\
\text { promoter, LEU2 }\end{array}$ & This study \\
\hline pYX242-HXK2nox & $\begin{array}{l}\text { pYX242-WS, noXE gene with HXK2 } \\
\text { promoter, LEU2 }\end{array}$ & This study \\
\hline pRS315-TEF1nox & $\begin{array}{l}\text { pRS315, noxE gene } \\
\text { with TEF1 promoter, LEU2 }\end{array}$ & This study \\
\hline $\mathrm{pJX1}$ & $\begin{array}{l}\text { YCplac33, XYL1 with TEF1 } \\
\text { promoter, XYL2 with TDH3 } \\
\text { promoter }\end{array}$ & {$[12]$} \\
\hline $\mathrm{pJX7}$ & $\begin{array}{l}\text { YEplac195, } 2 \mu, \text { Ru-xylA with TEF1 } \\
\text { promoter, URA3 }\end{array}$ & [28] \\
\hline
\end{tabular}

gas analyzer. All cultivations were carried out in defined medium containing $5 \mathrm{~g} / \mathrm{L}\left(\mathrm{NH}_{4}\right)_{2} \mathrm{SO}_{4}, 1.7 \mathrm{~g} / \mathrm{L}$ yeast nitrogen base, $20 \mathrm{~g} / \mathrm{L}$ glucose and $20 \mathrm{~g} / \mathrm{L}$ xylose. The initial $\mathrm{OD}_{600}$ was adjusted to 1 . All cultivations were performed in duplicate.

\section{Extracellular metabolite analysis}

Samples from the fermenters were centrifuged and filtered through a $0.45 \mu \mathrm{m}$ pore size syringe filter and frozen at $-20^{\circ} \mathrm{C}$ for subsequent analysis. Concentrations of glucose, xylose, xylitol, glycerol, ethanol and acetic acid were analyzed by HPLC. The separation column was an Aminex HPX-87H ion exchange column (Bio-Rad, Hercules, USA) operating at $45^{\circ} \mathrm{C}$ with mobile phase
$5 \mathrm{mM} \mathrm{H}_{2} \mathrm{SO}_{4}$ at a flow rate of $0.6 \mathrm{~mL} / \mathrm{min}$. The peaks were detected by RI and UV detectors.

\section{Cell mass determination}

The optical density of the culture at $600 \mathrm{~nm}$ was measured in a spectrophotometer (Eppendorf AG, 22331 Hamburg, Germany). The dry cell weight (DCW) was measured by filtering a known volume of the culture through a pre-dried and pre-weighed nitrocellulose filter (pore size $0.45 \mu \mathrm{m}$ ). The filters were dried at $105^{\circ} \mathrm{C}$ until their weight had stabilized, and re-weighed. The dry cell weight was the weight difference between the filter membrane with dried cells and the membrane without cells. The dry cell weight was estimated from the measured $\mathrm{OD}_{600}$-dry weight correlation, where $1 \mathrm{~g} / \mathrm{L}$ biomass equals $0.246 \times\left(\mathrm{OD}_{600}\right)-0.0012$.

\section{NADH oxidase activity measurement}

Samples were harvested during the mid-exponential phase of the cultivation and centrifuged immediately $(4,000 \mathrm{~g}$ at $1^{\circ} \mathrm{C}$ for $5 \mathrm{~min}$ ). Cell-free extracts were prepared using a Fast Prep cell homogenizer. NADH oxidase activity was assayed spectrophotometrically in $50 \mathrm{mM}$ potassium phosphate buffer (pH 7.0), 0.3 mM $\beta-\mathrm{NADH}$ and $0.3 \mathrm{mM}$ EDTA at $340 \mathrm{~nm}$, as previously described [43]. Protein concentrations were measured following the Bradford method. One unit (U) of enzyme activity was defined as the oxidation of $1.0 \mu \mathrm{mol} \mathrm{NADH}$ per min.

\section{$\mathrm{NAD}^{+}$and NADH quantification}

Samples were taken and quenched in $30 \mathrm{~mL}$ pure methanol in pre-weighed tubes maintained at $-40^{\circ} \mathrm{C}$. The cells were then collected by centrifugation at $-20^{\circ} \mathrm{C}$ at $12000 \mathrm{~g}$ for 5 minutes. Next, $1 \mathrm{ml}$ of $17 \%$ (v/v) alcoholic $1 \mathrm{M} \mathrm{KOH}$ (for $\mathrm{NADH}$ extraction) or $1 \mathrm{ml} 35 \%$ (v/v) $\mathrm{HClO}_{4}$ (for $\mathrm{NAD}^{+}$extraction) was added to the cell pellet. The extracts were frozen by liquid nitrogen, thawed and then neutralized by adding $2 \mathrm{M} \mathrm{HCl}$ (for $\mathrm{NADH}$ extraction) or $2 \mathrm{M} \mathrm{KOH}$ (for $\mathrm{NAD}^{+}$extraction). The cellular debris was removed by centrifuging at $12,000 \mathrm{~g}$ for $5 \mathrm{~min}$. Supernatants were transferred to new tubes and stored at $-80^{\circ} \mathrm{C}$. Intracellular $\mathrm{NAD}(\mathrm{H})$ concentrations were determined by HPLC as previously described [44].

\section{Real-time quantitative PCR (qPCR)}

Total RNA was isolated using UNIQ-10 spin column RNA extraction kits (Sangon Biological Engineering, China). The first cDNA strand was synthesized using the PrimeScript $^{\text {TM }}$ RT Reagent Kit (TaKaRa, Japan) and was used for qPCR amplification in the Light Cycle PCR System (SYBR Green Real-time PCR Master Mix, Japan). The reference gene was ACT1. The gene-specific primers are listed in Table 4. 


\section{Abbreviations}

$\mathrm{XI}$ : Xylose isomerase; XR: Xylose reductase; XDH: Xylitol dehydrogenase: NADH: Reduced form of nicotinamide adenine dinucleotide; DHAP: Dihydroxyacetone phosphate; GPD: Glycerol-3-phosphate dehydrogenase; GPP: Glycerol-3-phosphate phosphatase; EDTA: Ethylenediaminetetraacetic acid.

\section{Competing interests}

The authors declare that they have no competing interests.

\section{Authors' contributions}

$\mathrm{JH}$ designed the study, performed the data analysis and wrote the manuscript. SF performed the experiments and edited the manuscript. WC and LX performed some experiments. YS participated in design and drafted the manuscript. BX participated in the design and coordination and drafted the manuscript. All authors read and approved the final manuscript.

\section{Acknowledgments}

This work was supported by the National Key Basic Research Program (2011CB707405), the National High-Technology Research and Development Program of China under Grant (2012AA022106), the National Natural Science Foundation of China (31300037, 30970091, 31070096 and 31270151), and Independent Innovation Foundation of Shandong University, IIFSDU (2012 TB003). We thank Dr. Peter Kötter (Johann Wolfgang Goethe-University, Frankfurt, Germany) for supplying the CEN.PK113-5D strains and Prof. Jian Kong (Shandong University, Jinan, China) for providing the Lactococcus lactis noxE gene.

Received: 1 July 2013 Accepted: 8 February 2014

Published: 14 February 2014

\section{References}

1. Hahn-Hagerdal B, Karhumaa K, Jeppsson M, Gorwa-Grauslund MF: Metabolic engineering for pentose utilization in Saccharomyces cerevisiae. Adv Biochem Eng Biotechnol 2007, 108:147-177.

2. Hahn-Hagerdal B, Karhumaa K, Fonseca C, Spencer-Martins I, Gorwa-Grauslund MF: Towards industrial pentose-fermenting yeast strains. Appl Microbiol Biotechnol 2007, 74(5):937-953.

3. Jeffries TW: Engineering yeasts for xylose metabolism. Curr Opin Biotechnol 2006, 17(3):320-326.

4. Scalcinati G, Otero JM, Van Vleet JR, Jeffries TW, Olsson L, Nielsen J: Evolutionary engineering of Saccharomyces cerevisiae for efficient aerobic xylose consumption. FEMS Yeast Res 2012, 12(5):582-597.

5. Walfridsson M, Anderlund M, Bao X, Hahn-Hagerdal B: Expression of different levels of enzymes from the Pichia stipitis XYL1 and XYL2 genes in Saccharomyces cerevisiae and its effects on product formation during xylose utilisation. App/ Microbiol Biotechnol 1997, 48(2):218-224.

6. Kuyper M, Harhangi HR, Stave AK, Winkler AA, Jetten MS, de Laat WT, den Ridder JJ, Op den Camp HJ, van Dijken JP, Pronk JT: High-level functional expression of a fungal xylose isomerase: the key to efficient ethanolic fermentation of xylose by Saccharomyces cerevisiae? FEMS Yeast Res 2003, 4(1):69-78.

7. Kuyper M, Hartog MM, Toirkens MJ, Almering MJ, Winkler AA, van Dijken JP, Pronk JT: Metabolic engineering of a xylose-isomerase-expressing Saccharomyces cerevisiae strain for rapid anaerobic xylose fermentation. FEMS Yeast Res 2005, 5(4-5):399-409.

8. Kuyper M, Toirkens MJ, Diderich JA, Winkler AA, van Dijken JP, Pronk JT: Evolutionary engineering of mixed-sugar utilization by a xylose-fermenting Saccharomyces cerevisiae strain. FEMS Yeast Res 2005, 5(10):925-934

9. Kuyper M, Winkler AA, van Dijken JP, Pronk JT: Minimal metabolic engineering of Saccharomyces cerevisiae for efficient anaerobic xylose fermentation: a proof of principle. FEMS Yeast Res 2004, 4(6):655-664.

10. van Maris AJ, Winkler AA, Kuyper M, de Laat WT, van Dijken JP, Pronk JT: Development of efficient xylose fermentation in Saccharomyces cerevisiae: xylose isomerase as a key component. Adv Biochem Eng Biotechnol 2007, 108:179-204.

11. Zhou H, Cheng JS, Wang BL, Fink GR, Stephanopoulos G: Xylose isomerase overexpression along with engineering of the pentose phosphate pathway and evolutionary engineering enable rapid xylose utilization and ethanol production by Saccharomyces cerevisiae. Metab Eng 2012, 14(6):611-622
12. Peng B, Shen Y, Li X, Chen X, Hou J, Bao X: Improvement of xylose fermentation in respiratory-deficient xylose-fermenting Saccharomyces cerevisiae. Metab Eng 2012, 14(1):9-18.

13. Shen $Y$, Chen X, Peng B, Chen L, Hou J, Bao X: An efficient xylose-fermenting recombinant Saccharomyces cerevisiae strain obtained through adaptive evolution and its global transcription profile. Appl Microbiol Biotechno/ 2012 96(4):1079-1091.

14. Eliasson A, Christensson C, Wahlbom CF, Hahn-Hagerdal B: Anaerobic xylose fermentation by recombinant Saccharomyces cerevisiae carrying $X Y L 1, X Y L 2$, and XKS1 in mineral medium chemostat cultures. Appl Environ Microbiol 2000, 66(8):3381-3386.

15. Hou J, Vemuri GN, Bao X, Olsson L: Impact of overexpressing NADH kinase on glucose and xylose metabolism in recombinant xylose-utilizing Saccharomyces cerevisiae. Appl Microbiol Biotechnol 2009, 82(5):909-919.

16. Bengtsson O, Hahn-Hagerdal B, Gorwa-Grauslund MF: Xylose reductase from Pichia stipitis with altered coenzyme preference improves ethanolic xylose fermentation by recombinant Saccharomyces cerevisiae. Biotechnol Biofuels 2009, 2:9.

17. Hou J, Shen Y, Li XP, Bao XM: Effect of the reversal of coenzyme specificity by expression of mutated Pichia stipitis xylitol dehydrogenase in recombinant Saccharomyces cerevisiae. Lett Appl Microbiol 2007, 45(2):184-189.

18. Matsushika A, Watanabe S, Kodaki T, Makino K, Inoue H, Murakami K, Takimura O, Sawayama S: Expression of protein engineered $\mathrm{NADP}^{+}$-dependent xylitol dehydrogenase increases ethanol production from xylose in recombinant Saccharomyces cerevisiae. Appl Microbiol Biotechnol 2008, 81(2):243-255.

19. Verho R, Londesborough J, Penttila M, Richard P: Engineering redox cofactor regeneration for improved pentose fermentation in Saccharomyces cerevisiae. Appl Environ Microbiol 2003, 69(10):5892-5897.

20. Zhang GC, Liu JJ, Ding WT: Decreased xylitol formation during xylose fermentation in Saccharomyces cerevisiae due to overexpression of water-forming NADH oxidase. Appl Environ Microbiol 2012, 78(4):1081-1086

21. Bro C, Regenberg B, Forster J, Nielsen J: In silico aided metabolic engineering of Saccharomyces cerevisiae for improved bioethanol production. Metab Eng 2006, 8(2):102-111.

22. Grotkjaer T, Christakopoulos P, Nielsen J, Olsson L: Comparative metabolic network analysis of two xylose fermenting recombinant Saccharomyces cerevisiae strains. Metab Eng 2005, 7(5-6):437-444.

23. Lee SM, Jellison T, Alper HS: Directed evolution of xylose isomerase for improved xylose catabolism and fermentation in the yeast Saccharomyces cerevisiae. Appl Environ Microbio/ 2012, 78(16):5708-5716.

24. Madhavan A, Tamalampudi S, Ushida K, Kanai D, Katahira S, Srivastava A, Fukuda H, Bisaria VS, Kondo A: Xylose isomerase from polycentric fungus Orpinomyces: gene sequencing, cloning, and expression in Saccharomyces cerevisiae for bioconversion of xylose to ethanol. Appl Microbiol Biotechnol 2009, 82(6):1067-1078.

25. Brat D, Boles $E$, Wiedemann B: Functional expression of a bacterial xylose isomerase in Saccharomyces cerevisiae. Appl Environ Microbiol 2009, 75(8):2304-2311.

26. Hector R, Dien B, Cotta M, Mertens J: Growth and fermentation of D-xylose by Saccharomyces cerevisiae expressing a novel D-xylose isomerase originating from the bacterium Prevotella ruminicola TC2-24. Biotechnol Biofuels 2013, 6:84.

27. Madhavan A, Tamalampudi S, Srivastava A, Fukuda H, Bisaria VS, Kondo A: Alcoholic fermentation of xylose and mixed sugars using recombinant Saccharomyces cerevisiae engineered for xylose utilization. Appl Microbiol Biotechnol 2009, 82(6):1037-1047.

28. Bao $X$, Shen $Y$, Ge R: Nucleic acid molecule for encoding xylose isomerase and xylose isomerase encoded by the nucleic acid molecule. PCT Patent 2011, 13:388,225.

29. Nissen TL, Hamann CW, Kielland-Brandt MC, Nielsen J, Villadsen J: Anaerobic and aerobic batch cultivations of Saccharomyces cerevisiae mutants impaired in glycerol synthesis. Yeast 2000, 16(5):463-474.

30. Guo ZP, Zhang L, Ding ZY, Wang ZX, Shi GY: Improving ethanol productivity by modification of glycolytic redox factor generation in glycerol-3-phosphate dehydrogenase mutants of an industrial ethanol yeast. J Ind Microbiol Biotechnol 2011, 38:935-943.

31. Blomberg A, Adler L: Physiology of osmotolerance in fungi. Adv Microb Physiol 1992, 33:145-212 
32. Guo ZP, Zhang L, Ding ZY, Shi GY: Minimization of glycerol synthesis in industrial ethanol yeast without influencing its fermentation performance. Metab Eng 2011, 13(1):49-59.

33. Yu KO, Kim SW, Han SO: Reduction of glycerol production to improve ethanol yield in an engineered Saccharomyces cerevisiae using glycerol as a substrate. J Biotechnol 2010, 150(2):209-214.

34. Pagliardini J, Hubmann G, Alfenore S, Nevoigt E, Bideaux C, Guillouet SE: The metabolic costs of improving ethanol yield by reducing glycerol formation capacity under anaerobic conditions in Saccharomyces cerevisiae. Microb Cell Fact 2013, 12(1):29.

35. Hou J, Lages NF, Oldiges M, Vemuri GN: Metabolic impact of redox cofactor perturbations in Saccharomyces cerevisiae. Metab Eng 2009, 11(4-5):253-261.

36. Nissen TL, Kielland-Brandt MC, Nielsen J, Villadsen J: Optimization of ethanol production in Saccharomyces cerevisiae by metabolic engineering of the ammonium assimilation. Metab Eng 2000, 2(1):69-77.

37. Zhang L, Tang Y, Guo ZP, Ding ZY, Shi GY: Improving the ethanol yield by reducing glycerol formation using cofactor regulation in Saccharomyces cerevisiae. Biotechnol Lett 2011, 33(7):1375-1380.

38. van Dijken JP, van den Bosch E, Hermans JJ, de Miranda LR, Scheffers WA: Alcoholic fermentation by 'non-fermentative' yeasts. Yeast 1986, 2(2):123-127.

39. Verduyn C, Postma E, Scheffers WA, van Dijken JP: Physiology of Saccharomyces cerevisiae in anaerobic glucose-limited chemostat cultures. J Gen microbiol 1990, 136(3):395-403.

40. Rigoulet M, Aguilaniu H, Averet N, Bunoust O, Camougrand N, Grandier-Vazeille X Larsson C, Pahlman IL, Manon S, Gustafsson L: Organization and regulation of the cytosolic NADH metabolism in the yeast Saccharomyces cerevisiae. Mol Cell Biochem 2004, 256-257(1-2):73-81.

41. Ansell R, Granath K, Hohmann S, Thevelein JM, Adler L: The two isoenzymes for yeast $\mathrm{NAD}^{+}$-dependent glycerol 3-phosphate dehydrogenase encoded by GPD1 and GPD2 have distinct roles in osmoadaptation and redox regulation. EMBO J 1997, 16(9):2179-2187.

42. Wang C, Shen Y, Zhang Y, Suo F, Hou J, Bao X: Improvement of L-arabinose fermentation by modifying the metabolic pathway and transport in Saccharomyces cerevisiae. Biomed Res Int 2013, 2013:461204.

43. Vemuri GN, Eiteman MA, McEwen JE, Olsson L, Nielsen J: Increasing NADH oxidation reduces overflow metabolism in Saccharomyces cerevisiae. Proc Natl Acad Sci U S A 2007, 104(7):2402-2407.

44. Jones DP: Determination of pyridine dinucleotides in cell extracts by high-performance liquid chromatography. J Chromatogr 1981, 225(2):446-449.

doi:10.1186/1472-6750-14-13

Cite this article as: Hou et al.: Fine-tuning of NADH oxidase decreases byproduct accumulation in respiration deficient xylose metabolic Saccharomyces cerevisiae. BMC Biotechnology 2014 14:13.

\section{Submit your next manuscript to BioMed Central and take full advantage of:}

- Convenient online submission

- Thorough peer review

- No space constraints or color figure charges

- Immediate publication on acceptance

- Inclusion in PubMed, CAS, Scopus and Google Scholar

- Research which is freely available for redistribution 